\title{
Review of Water Network Analysis and Validation of SCALER Hydraulic Simulator
}

\author{
Henrique da Silva Pizzo ${ }^{1,2}$ *, João Paulo de Carvalho Ignácioo ${ }^{1,3}$, Marcus Vinicius do Nascimento ${ }^{1}$ \\ ${ }^{I}$ College of Civil Engineering, Estácio University of Juiz de Fora, Minas Gerais, Brazil \\ ${ }^{2}$ Department of Hydraulic Measurements, Municipal Water and Sewage Company of Juiz de Fora, Brazil \\ ${ }^{3}$ Department of Software Development, Inspell Softwares, Juiz de Fora, Brazil \\ henriquepizzo.estacio@gmail.com,jpcarvalhoi2@gmail.com,documentosmv2017@hotmail.com
}

\begin{abstract}
The article intends to present the validation stage of a software to model and simulate hydraulic networks for water distribution, the SCALER, through its application to a real system, with many branches, with a model previously developed and verified using the EPANET software. SCALER was developed in 2020 and 2021 and, until then, had only been applied to networks with a relatively small number of branches. After discussing topics related to hydraulic modeling of distribution networks, techniques and applications, a brief review of the fundamentals of SCALER is carried out, passing on to its application to the case at hand, which is the Vila Joaniza community, in the municipality of Rio de Janeiro. Data from image, scheme and table are used to assist in the description of the local situation and respective distribution network, with the objective of assessing whether the nodal pressures obtained by SCALER are sufficiently similar to those obtained by EPANET, in order to ensure the proper functioning of the software. After this step, and the calculations have been made by the program, an operation screen, the generated graph of the local situation and a table with the comparison of absolute and percentage deviations between the nodal pressures resulting from the SCALER and those obtained with the EPANET are inserted, confirming that the deviation values are quite small, which validates SCALER as a software also applicable to networks with many branches.
\end{abstract}

Keywords: hydraulic distribution networks, systems modeling, water supply, software validation

Received: November 08, 2021/Accepted: December 25, 2021/Online: January 01, 2022

\section{INTRODUCTION}

Water is an essential natural resource, considered strategic due to its importance for the lives of people and societies. Reference [1] points that, by understanding the importance of water for existence, it is possible to measure how fundamental its rational use is, as well as how valuable research and hydraulic solutions are for its better use. Always present throughout human history, due to the essential nature of water for life on the planet, hydraulics was directly responsible for civilizing development and population growth, which in turn, consequently generated an increase in the consumption of that natural resource, making the development of strategic solutions for the proper use of water.

Since then, the concern with this resource has been prioritized, as its access has become limited. A study released in 2019 by the World Health Organization (WHO) and the United Nations Children's Fund (UNICEF) is cited in [2], in which it is estimated that 2.2 billion people did not have, at that time, access to securely managed drinking water services. Given this scenario, the need for knowledge about the issue of sanitation to solve these and other issues is evident, especially for cities, where the drinking water supply is one of the most important systems for its population and is directly linked to issues public health, social, industrial and economic development. The issue of water supply and distribution is highly relevant, requiring an optimized management of water and its forms of allocation, both qualitatively and quantitatively, especially when taking into account the public health issues arising from its incorrect distribution.

The supply system is defined by a set of works, equipment and services intended to supply drinking water to a community for the purposes of domestic consumption, public services and industrial consumption [3]. The water supplied by the system must be in sufficient quantity and of the best quality, from a physical, chemical and bacteriological point of yiew. For the

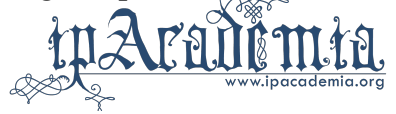


implementation of a water supply system, it is necessary to prepare studies and projects with a view to defining the works to be undertaken. These works must have their capacity determined not only for the current needs, but also for the future service of the community, with construction being planned in stages.

According to [4], over the last few decades, a huge amount of effort has gone into building computer models for use in water resource planning and management. In all elements of water management, powerful generic software packages are becoming increasingly crucial. With recent improvements in computer technology, virtually everyone working in the water resources and environmental fields now has easy access to desktop computers with all of the hardware capabilities required to run the vast array of available models.

One of the most significant professional problems and possibilities confronting water and environmental practitioners and academics today is to utilize and leverage the fast rising sources of available data and computing capacity. Sensor expansion, large-scale and extensive data acquisition, increasingly sophisticated modeling tools, digital infrastructure, the internet of things, and the rollout of $5 \mathrm{G}$ wireless networks will allow for the development of far more mutualistic relationship between rural residents, municipalities, urban citizens, and businesses [5]. A significant modeling application is the analysis of municipal water distribution networks.

Currently, in more developed urban centers, the greatest deficiencies observed in water supply systems are mainly due to the deterioration of older systems. This occurs especially in the part of the water distribution networks, with old pipes presenting frequent problems of ruptures and water leaks, or even the lack of supply in urban areas that present rapid and disorderly growth. Thus, for these urban centers, and even for smaller areas, the needs for adequacy of water supply services are linked to the rehabilitation of older water supply and distribution networks, as well as the construction and expansion of systems to meet the new growth areas [6]. The implementation, maintenance and operation of distribution networks end up having its cost diluted by the entire population and, thus, the importance of a correct dimensioning of the systems emerges, avoiding waste and fulfilling its function with quality.

\section{WATER Distribution Network MODElS}

\section{A. Overview}

In water distribution networks, hydraulic modeling is used to forecast hydraulic characteristics such as water velocity, flow rate, and pressure. Predictions can be made at various places throughout the network, as well as at the chosen seasons, dates, and periods. As a result, hydraulic characteristics may be predicted in space and time [7]. In the early days of water distribution computer modeling, simulations were primarily used by engineers to solve design problems, to plan fully functional water distribution systems [8]. The use of computer programs became standard practice, initially, because engineers may focus on design decisions because automated calculations save them from tiresome, iterative computations. Second, because models can account for considerably more of the complexity of real-world systems than manual calculations, they boost the engineer's confidence that the design will function after it is implemented. Finally, the simplicity and speed with which models may be employed allows engineers to investigate many more choices under a variety of scenarios, resulting in more cost-effective and resilient solutions.

There is no one strategy to utilize models that is completely right. Reference [9] describes how the application of a model for design goals varies depending on whether the model is used for master planning, preliminary design, subdivision development, or system rehabilitation. As detailed in the study, each model type has a distinct aim and set of attributes.

Models have become more sophisticated and easier to use as software technology has advanced and, because of that, operational workers have adopted computer simulations as a tool to assist them in keeping the distribution system functioning properly. As a result, models began to be utilized to address ongoing issues, examine suggested operational improvements, and plan for unexpected situations. Instead of relying to trialand-error adjustments in the actual system, the operator may discover the reasons of system issues and propose alternatives that will work the first time by comparing model results with field operations [8]. Some aspects and applications related to water supply network models are described.

\section{B. Assessment of Operation, Management and Maintenance}

Reference [10] points that the increasing water demand in the cities and the unplanned expansion of the water supply networks have caused deficiencies regarding to pressures and flows in systems. The most appropriate solution to avoid such problems usually depends on a set of initiatives, which are defined by the hydraulic diagnosis of the water supply network and the evaluation of different alternatives. The hydraulic simulators are key tools in the development process of these studies. It's presented an initial hydraulic diagnosis of the water supply network of Várzea Alegre and the first results obtained with the EPANET hydraulic simulator. The observed data indicate pressure values under the minimum recommended by technical standards, and water consumption with high variability in the daily and monthly scale. On the other hand, the simulations show the need to obtain more detailed data from the water supply network to set up the hydraulic simulator.

According to [11], to investigate the behavior of water systems under the action of intermittent pumping, a water distribution network in Jenin city was taken as a case study. A system modeling procedure was carried out, including operational factors, ways of operating and managing the system, with each agglomeration of houses represented by a consumption node, and the control made by check valves, modeling the system through the WaterCAD Program. The results showed that the network was exposed to relatively high values of pressure and velocity, which have negative effects on the performance of the network. Comparisons between the modeled pressure results and those measured in the field indicated small to reasonable differences.

The extreme learning machine (ELM) develops [12] a unique failure rate prediction model to offer essential information needed for optimum continuous maintenance/rehabilitation of a water network, namely the 
projected times for the future failures of specific pipes within the network. The created ELM model was trained utilizing more than 9500 cases of pipe failure in the Greater Toronto Area from 1920 to 2005, including pipe variables such as pipe length, diameter, material, and previously documented failures as inputs. The simulations reveal that recent, widespread use of cement mortar pipe coating and cathodic protection has greatly enhanced their longevity. The pipe protection technique is included as a pipe attribute in the predictive model, which can represent the influence of different pipe protection methods on the predicted time to the next pipe failure in its predictions. The proposed ELM outperforms other known machine learning techniques such as backpropagation-trained feed-forward artificial neural networks, support vector regression, and nonlinear regression in terms of prediction accuracy. The models' usefulness gives valuable insights for planning and budgeting for water main monitoring, repair, and rehabilitation.

The capacity to provide sufficient pressure and flow is inextricably linked to water distribution network performance. According to [13], performance is also determined by how efficiently these requirements are met. As a result, a performance metric based on efficiency is offered. It's the geometric mean of four performance metrics: dependability, vulnerability, resilience, and connectedness. These are based on the system's energy efficiency, hydraulic capacity, and structural ability to provide water in a variety of situations. The criteria are tested in two example circuits and modifications of these, allowing evaluation of their usefulness, sensitivity to changes in the system, and comparison to current criteria. Variations reflect several redundancy raising tactics that have been proven to improve performance. The suggested performance index typically follows the same trend as the preceding indices, increasing with network pressure. Moreover, it fluctuates and penalizes networks that experience unreasonably high loads. The index automatically complies with the network's energy and mass balances since it is based on energy and demand efficiency measurements. Furthermore, the new measure is simple to understand and can be used to a wide range of systems, from complicated to multi-scenarios.

A work that aimed to model and simulate the water distribution network in the district of Vazantes, located in the city of Aracoiaba, considering current and future demand, is presented in [14]. To carry out the work, the EPANET software was used. Three simulations were carried out, the first one to verify the solution adopted to solve the problem of high pressures in the network that had been causing leaks. The next one had the objective of verifying the behavior of the network in face of future demand. Finally, the last simulation allowed to evaluate the demand in which non-supplied points are observed, that is, the network collapse demand. From the simulation results, it was verified that the proposed solution to eliminate high pressures was efficient and that the network offers conditions to work with future demand.

As stated by [15] performance of the network is understood as the power to supply a specified quantity of water at an acceptable level of pressure and quality. A good performance indicator is a useful tool for more effective water system management. It is offered a technique for assessing the performance of water distribution networks based on quality criteria (such as residual chlorine, water age, and so on) and the head driven simulation method (HDSM). A pressure dependent simulation model is used for hydraulic study of water networks. The approach can more accurately forecast the hydraulic behavior of the system, especially during abnormal and critical situations (e.g., outage of pumps and reservoirs, pipe breaks, leakage, excess demands, etc.). In addition, for the analysis of water quality metrics, a discrete-volume element method (DVEM) is used. The system's quality performance is then analyzed using penalty curves based on standard codes for quality criteria. The new methodology's use is demonstrated by assessing a test network. The findings are contrasted to those of the widely used EPANET 2 software's water quality simulator, which employs the demand-driven simulation method (DDSM) as its hydraulic simulation engine. Regardless of nodal pressure fluctuations, the DDSM models take fixed demands into account. Taking HDSM into account results in various pipe velocities and, as a result, different quality parameter values. The conclusions of [15] demonstrated that the approach can aid in more accurately assessing the performance of quality metrics in water distribution networks than existing demand-driven simulation-based models.

A study is presented in which the objective was to measure the residual chlorine concentrations in drinking water, which comes out of the water supply plants at Babylon University. To assess the effectiveness of the quantitative-qualitative of the EPANET program, the Babylon water network was chosen as a case study. This entailed determining the number, locations, and dose of onsite chlorine injection points necessary to boost chlorine concentrations to acceptable levels in the network's other nodes. Between December 2016 and April 2017, 80 tap water samples were collected from 10 different sites within Babylon University's water network. These samples were examined twice a week, three times a day, to determine residual chlorine concentrations. The major finding of this study is that onsite injection can enhance the concentration of chlorine in Babylon University's water supply network [16].

An approach presented in [17] shows the simulation of Gukook's potable water distribution networks are undergoing residual chlorine degradation. The EPANET program is used to estimate and anticipate chlorine concentrations at various locations in the water network. The data necessary as program inputs (pipe characteristics) were obtained from the Baghdad municipality, and parameters influencing residual chlorine content, such as $\mathrm{pH}$, temperature, pressure, and flow rate, were assessed. From November 2016 to July 2017, twenty-five samples were examined. The residual chlorine levels ranged from $0.2-2 \mathrm{mg} / \mathrm{L}$, the $\mathrm{pH}$ levels ranged from 7.6-8.2, and the pressure was quite low in this area. Errors were examined using statistical analysis. The adjusted model's estimated values were extremely close to the actual concentrations recorded in the field at several sampling places on different days.

Physical loss in network includes leakages from broken or cracked pipes, leakages from branch connection points and weir losses in storages. Total water budget not only includes physical losses but also illegal consumptions, that is not invoiced. For instance, Istanbul Municipality accomplished to decrease water loss from $38 \%$ in 2002 to $27 \%$ in 2013 with effective measures. A study aimed to give the dimension of existing water loss 
problems in Turkey and to present improvement works of municipalities was done, and necessary strategies to overcome the problem was also reviewed. Water meters were checked by an automation system and leakage detection devices were used to determine physical troubles. For hydraulic modelling, pressure was measured at 55 points, $62 \mathrm{~km}$ network length was renewed, data for 1500 buildings were updated, water consumption data of all subscribers and SCADA data were evaluated [18].

The energy related to the water losses is commonly thought to be proportional to the percentage of water loss obtained in water balances. However, according to [19], this hypothesis had not yet been proven since flow does not vary linearly with headlosses in water supply systems. It is addressed that topdown and bottom-up tactics were used to attain validation. The initial method takes little data, offers a summary of the key water-energy balance components, and offers an effective diagnostic of energy inefficiencies by calculating the ratio of total energy in excess linked to pumps, water losses, and networks. The other method necessitates the use of calibrated hydraulic models and gives a complete analysis of the aforementioned water-energy balance components. The results validate the stated hypothesis and reveal that the most important energy inefficiencies are connected with excess energy, pumping, and water losses, which each account for up to $40 \%$ of total input energy. Pipe friction and valve headloss, each of which can account for up to $15 \%$ of total input energy, are less major components.

\section{Optimization, Rehabilitation and GIS Tools}

For several years, the optimization of urban water distribution networks has been a crucial problem in the water business. The optimum distribution network design seeks the best option for transporting water from the reservoir to users at the lowest possible cost [20]. It's presented a study in which the fast messy genetic algorithms (FMGA) tool in the hydraulic model was used to optimize the water distribution network of a portion of Ilam city for three alternative pipe networks. Furthermore, these networks were optimized in MATLAB using a mix of EPANET and an in-house created binary genetic algorithm. The costs of the optimized hydraulic networks of polyethylene and polypropylene pipes were reduced by $20.56 \%$ and $52.94 \%$, respectively, when compared to the consulting firm's original designs, while the cost of the glass fiber reinforced plastic pipe (GRP) pipe network increased by $12.61 \%$. In addition, the results of a newly designed algorithm for polyethylene pipe were reduced by $22.13 \%$.

Reference [21] points that water utilities are more significant as there is a growing need to boost operation while also enhancing the environment so that their behavior can be completely understood and the overall process can be optimized. It provides a work that presents simulation and control of the city of Gaziantep's water supply system for management reasons. The primary goals are to maintain the proper operation of a water distribution system and to control water flow and heads by managing the water pumps. The structure is comprised of a series of pumping stations that send water to middle storage reservoirs. The model was created by combining prominent system variables that reflect active and passive dynamical aspects. Nonlinear interaction between flows and tank heads is also accounted for in the hydraulic models. The polynomial $\mathrm{H}_{\infty}$ optimization approach is used to create a level regulator that controls the flow and heads of water through the system. The entire simulation was performed, and the results are shown and compared to the measured data in real time.

According to [22], water network optimization service is set by determining the best cost-performance trade-off (e.g., resilience and leakage). The network (re)design is a significant difficulty in the field of water distribution systems (WDSs). While complex network analysis (CNA) has been used to investigate the complexity of WDS, it has been noted out that there is still a paucity of research on CNA of ideal water systems. Several graph features are found based on a systematic CNA of Pareto-optimal solutions of different WDSs, and a newly developed CNA design technique for WDSs is provided. The findings reveal that the generated designs are equivalent to those achieved using evolutionary optimization, but the CNA technique is usable for large networks (e.g., 150,000 pipes) with significantly less computing effort (runtime reduction up to 5 orders of magnitude).

An approach for managing the repair and replacement of water distribution networks utilizing hydraulic and geographic information systems models is described [23]. Geospatial information systems and hydraulic software are linked via a preprocessor procedure. Hydraulic characteristics, as well as pipe information, are utilized to estimate the necessary rehabilitation plans based on a variety of factors. Pipe break and leakage studies, hydraulic and quality performance, and network mechanical reliability are among the recommended indexes. A unique method for calculating leakage values across the network is also presented. The proposed model was used to replace $4 \mathrm{~km}$ $40 \mathrm{~mm}$ galvanized pipes instead of $11 \mathrm{~km} 100 \mathrm{~mm}$ asbestoscement pipes in a real-world case study. In comparison to the standard technique, which only considers the number of bursts as a major criterion, the recommended geographic information system-based model offers more realistic findings with lower costs for repair projects.

A geographic information systems model was developed to manage the assets of the water distribution networks in the Karrada region and to geometrically evaluate the network [24]. Tools were made available to investigate about the possibility of network breakdowns and assist maintenance professionals in taking immediate action to identify problems in the system (for example, failure in pipes, service areas, etc.), followed by quick solutions to optimize network maintenance work, providing a framework for continuous improvement. Finally, the research suggested that authorities create a comprehensive central database for water networks that is constantly updated, and that they take use of modern water distribution network management program upgrades to assist maintenance experts in monitoring network problems.

Reference [25] explores the issues of water losses and leakages in distribution systems, with a reasoning its causes and consequences on various aspects of life, as well as an elaboration of the probability of successfully using geospatial techniques to contribute to the management of this matter. It is offered a first impression of an innovative technology for real- 
time leak detection in water distribution networks. It is dependent on the usage of a SCADA system to provide real-time pressure data at various locations throughout the network, which can then be analyzed using hydraulic analysis tools.

\section{Calibration and Monitoring Stations}

According to [26], because water distribution system networks are designed and managed using verification models, determining the input data for them is critical. A decent model calibration with realistic results may be produced with a limited number of measurements: flow in pipes and pressure in nodes. The examination of a novel model capable of providing suggestions on the choosing of measurement locations to acquire site data is provided. All studies were performed on literature networks initially, and subsequently on a real network using a novel technique based on sensitivity matrices.

To predict the water supply system of Al-Hakeem Quarter in Maqil district in the Governorate of Basrah, a hydraulic network model was built using the EPANET application. The model is calibrated in 5 joints based on the measured head. The Bourdon gauge is used to measure head at certain intersections. The model's best outcomes are chosen through a trial and error method based on three common statistical coefficients (root mean squared error, standard error, and coefficient of correlation). This model can be utilized if any modifications, such as the installation of an upper reservoir to the region, the addition of another pumping station, or network extension, occur in the future [27].

Reference [28] demonstrates how to calibrate a hydraulic model using a genetic algorithm (GA). It is used to a real-world network and optimizes the configurations of control valves for calibration at various intervals. A complete case study, GA calibration model, methodology, and calibrated model results are explained in depth. The following stage is determining appropriate sensor positions with a newly designed software application called S-PLACE GA, including considerations concerning performance.

In order to develop a calibration model, [29] couples a hydraulic simulator to an algorithm to search for extreme points of functions, known as the Nelder-Mead optimizer. This procedure aims to ensure the convergence process between the hydraulic model and physical reality. The result of this coupling is known as the Hybrid Model.

Reference [30] demonstrates a strategy based on the Demand Coverage Index (DCI). Because nodal demands alter over time, the optimization addresses extended period unstable hydraulics. The approach is implemented in a genetic algorithm architecture for collaboration with the EPANET program and is illustrated using sample applications. The results demonstrate that the set of optimum monitoring station sites generated using the DCI technique represents the decision variables better than other methods under diverse demand patterns.

It is introduced in [31] an algorithmic process that incorporates leakage losses and the pressure dependency of requests, linked to the hydraulic simulator EPANET 2, and use hypothetical network data for calibration in terms of absolute roughness and leak model parameters. In this case, inverse models computed using genetic algorithms (GA) technology and a hybrid approach are applied (GA and Simplex Method Nelder and Mead).

A method to identify monitoring stations is discussed in [32]. Preliminarily, it was determined which were the priority pipelines, through a sensitivity matrix. A scheme was then proposed to verify which nodes had a greater impact on the roughness of those pipes, that is, the nodes that cannot be left out of the monitoring process. The operationalization was obtained by inversion of the values of the numerical derivatives, components of the initial matrix, generated by the variation of the nodal loads with a unitary variation of the pipe roughness.

\section{E. Sizing Techniques and Comparisons Among Models}

References [33], [34], [35] describe, respectively, the process of sizing supply systems in Aram Village, Zin City, and New Zanco Village, Erbil city. They were performed by hand calculations in Excel spreadsheets, and using the EPANET program. As told by [36] Vila Joaniza, in the city of Rio de Janeiro, is a community with relatively old occupation, which has grown a lot since the 1980s. A study of conception of water supply system for that community is presented in [37]. To make this conception, it was adopted economic and technical criteria. The network, consisting of 52 sections, was dimensioned by hand-calculated Excel tables and verified using EPANET. Additional considerations, such as reservoir capacity calculation and cost estimation, were addressed in the aforementioned study.

As described in [38], the design of a water distribution network must define the operating pressures, also those resulting from hydraulic transients, the internal diameter of the pipes, the flow velocities, with an evaluation of the headlosses and establishing the hydraulic operating conditions. For the hydraulic dimensioning of the pipes, the Hazen-Williams coefficient or equivalent of the universal equation must be considered for the project horizon, as well as aging, encrustation and deposition on the pipe walls. The coefficients must be collected in the field or, if field evaluations are not possible, values explained in the theory of hydraulic manuals must be adopted.

For dealing with the NP-hard and computationally costly discrete, combinatorial, multi-objective design of water distribution systems (WDSs), a novel hybrid optimizer termed genetically adaptive leaping algorithm for approximation and diversity (GALAXY) is suggested [39]. Its advantage is its ability to significantly reduce parameterization issues and excessive computational cost. It adheres to the generative structure of multi-objective evolutionary algorithms (MOEAs) and has six search operators as well as numerous essential strategies. These operators are chosen based on their capacity to leap in the goal space from both a global and a local search standpoint. These methodologies direct optimization while concurrently balancing exploration and exploitation features. Its outstanding characteristic is that it removes the bulk of parameters, making it both robust and user-friendly. According to the company, comparative research on five benchmark WDS design difficulties between GALAXY and three sample MOEAs validate its competitiveness. The study guarantees that GALAXY can efficiently and consistently find superior convergent and distributed frontier solutions, suggesting a 
considerably more balanced capacity between global and local search. Furthermore, as the complexity of the design challenge grows, its benefits over other MOEAs become increasingly significant.

The time-marching approach (TMA) is a strategy for finding the true permanent regime as a result of a modeler-created hypothetical temporary condition. It has the benefit of presenting a physical convergence (apparently actual) in time, via a fictitious transient, to the eventual permanent regime [40]. Applications of the TMA method are presented in [41], to permanent analysis and also for extensive period, by the model SPERTS. It is stated that the benefit of this approach over other methodologies of network determination is its real convergence when following the transitory evolution, reaching the final permanent regime, to the detriment of the numerical iterative process of the other methods, not to mention the fact that these are matrices, resulting in a sequence of applications of systems of equations, which have peculiarities for resolution that should always be examined. Additional benefit of the TMA approach is that it may be used to non-permanent regime circumstances since the constituent equations are hydraulic transient formulas.

Reference [42] discusses the Flow program as a valuable teaching and useful framework, addressing both theoretical and practical issues. Visual Studio 2017 and the programming language C Sharp were used to create the product. Water supply systems, pumps, closed pipelines, hydraulic transients, and open channels are among the major points encased by the software system. Because of its user-friendly appearance and precise findings, the program has showed significant promise as a tool for hydraulic computations. The system was applied to a distribution network of a subdivision in the city of Juiz de Fora and the values of nodal heads were compared to those previously obtained by the local sanitation company. The absolute and percentage maximum deviations were, respectively, $0.032 \mathrm{mH} 2 \mathrm{O}$ and $0.18 \%$, confirming the good functioning of the Flow software. Other adherence and error indexes are analyzed in the work.

Performance, facilities and difficulties in use, referring to three hydraulic simulators - the EPANET, the WaterCAD and the UFC System - are investigated and debated in [43]. The chosen location to be used as a case study is located in the city of Rio de Janeiro, within the limits of the Campo Grande neighborhood. Despite the positive points of the three systems, analyzing the comparative matrix presented, it could be seen that WaterCAD had more positive evaluations, which does not necessarily imply that this is the best of the three models, but for the items evaluated, have been the one with the best performance for the proposed work.

Reference [44] proposes a methodology for sizing hydraulic networks, considering the cost of implementing the pipes and adequate pressure values, with the consequent reduction in energy losses in the system. In order to achieve these goals, four computational models were studied: RedemWeb, EPANET, Lenhsnet and UFC-4. Case studies were carried out with two water distribution networks available in the literature. The results achieved by Lenhsnet showed adequate dimensions for the operation of the networks, despite presenting, in some stretches, high headlosses. With the UFC-4, where headloss can be limited, the dimensioning was not possible due to technical problems in the application of the computer program. RedemWeb and EPANET also presented adequate sizing results, but they did not allow the optimization of results and, therefore, they had higher expenses with the pipes.

\section{F. The SCALER Software}

Reference [45] introduces the SCALER software, a light and simple system which makes it possible to carry out the dimensioning of branched water distribution networks, calculating the diameters and headlosses in each stretch, indicating the pressures available at each node and reservoir water level to meet the criteria previously established of minimum pressure at the most unfavorable point of the network. At the final results are presented and compared by the SCALER software with bibliography data about hydraulic networks, using a relatively small network, with 11 branches, indicating absolute and percentage maximum deviations as, respectively, $0.030 \mathrm{mH} 2 \mathrm{O}$ and $0.11 \%$. The SCALER system is a free desktop application, developed exclusively for Microsoft Windows 7 Operating System or higher, and 32-bit or 64-bit processor architecture. The programming language used was Delphi, through its free version, Delphi Community Edition. The user can define the headlosses to be calculated using the DarcyWeisbach formula (1), with the coefficient of friction being determined by the Enio Tourasse formula (2) [46], or by the Hazen-Williams equation (3).

$$
\begin{gathered}
h_{f}=f \frac{L}{D} \frac{V^{2}}{2 g} \\
f=\left(1,4 \frac{\varepsilon}{D}+0,1004\right) \cdot\left(\frac{\varepsilon}{D}+5 \cdot 10^{-5}+\frac{72}{R e}\right)^{0,24} \\
h_{f}=10,643 Q^{1,85} C^{-1,85} D^{-4,87} L
\end{gathered}
$$

Where $h_{f}$ is the headloss (m), $f$ is the coefficient of friction (dimensionless), $L$ is the pipeline length (m), $D$ is the pipe diameter $(\mathrm{m}), V$ is the average flow velocity $(\mathrm{m} / \mathrm{s}), g$ is the acceleration of gravity $(\mathrm{m} / \mathrm{s} 2), \varepsilon$ is the inner tube roughness $(\mathrm{m})$, $R e$ is the Reynolds Number (dimensionless), $Q$ is the flow rate $(\mathrm{m} 3 / \mathrm{s})$, and $C$ is the roughness coefficient (empirical).

The software is very intuitive, with simple screens for input data, as illustrated in Fig. 1. These are the total number of inhabitants or the total flow to be distributed; the length of the sections; the pipe roughness factor, whatever the headloss formula chosen to be used; and the terrain levels. SCALER allows the diameters of the pipes and the water level in the reservoir to be preset, or variable as a function of maximum speeds and minimum pressures, respectively situations for simulating existing systems and for sizing new systems. In case of sizing, the diameters can be determined by (4), presented in [3], in order to limit the flow velocity in the pipes.

$$
V=0,6+1,5 D
$$

Quantities and respective units have already been defined previously. 


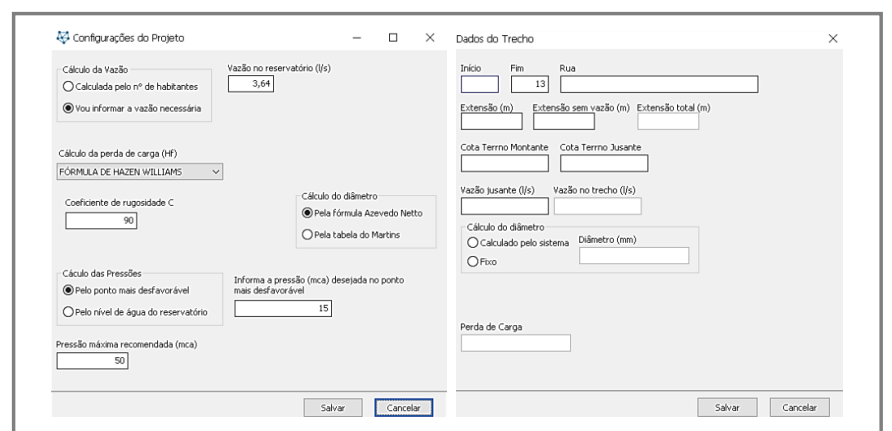

Fig. 1. Input data forms

It is known that the total energy in a generic node $i$ is given by Bernoulli (5) and, since the kinetic energy can be neglected in water distribution networks, because limitations of flow velocity, appears the piezometric head (6)

$$
\begin{gathered}
E_{i}=\frac{V_{i}^{2}}{2 g}+\frac{p_{i}}{\gamma}+Z_{i} \\
P H_{i}=\frac{p_{i}}{\gamma}+Z_{i}
\end{gathered}
$$

Where $E_{i}$ is the total energy, $\left(V_{i}^{2} / 2 \mathrm{~g}\right)$ is the kinetic energy, $\left(p_{i} / \gamma\right)$ is the pressure energy (or nodal pressure), $Z_{i}$ is the gravitational potential energy (or terrain level), $\mathrm{PH}_{i}$ is the piezometric head, all of them in (m), $p_{i}$ is the nodal pressure $(\mathrm{N} / \mathrm{m} 2)$, and $\gamma$ is the specific weight $(\mathrm{N} / \mathrm{m} 3)$. Another quantities and respective units have already been described previously.

Furthermore, it is known that the pizometric head in a downstream node is equal to the piezometric head in an upstream node minus the headloss in the connecting section, as written in (7)

$$
P H_{\text {downstream }}=P H_{\text {upstream }}-h_{\text {fsection }}
$$

Coupling (6) e (7) it is possible to determine all the nodal pressures of the network.

Fig. 2 shows a SCALER result screen. The related quantities are branches, extensions, flows, diameters, headlosses, terrain levels, hydraulic heads, and nodal pressures. In addition to the results table, the system performs a graphical representation of the network released.

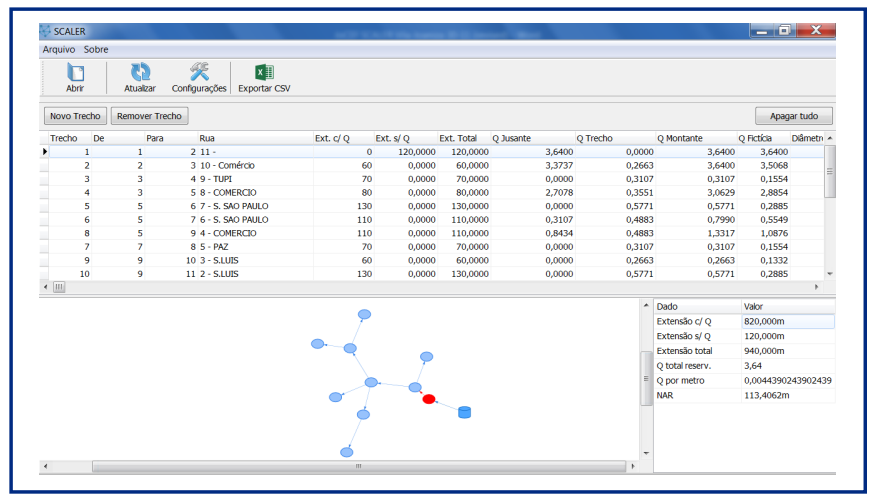

Fig. 2. SCALER interface

\section{Materials AND MethodS}

The SCALER software was used to simulate the hydraulic behavior of the water distribution network for the Vila Joaniza community. Fig. 3 presents a local image [36]. The purpose is that the pressure values at each node, obtained by SCALER, are then contrasted with those before obtained by EPANET and presented in [37], in order to verify SCALER accuracy also for large networks.

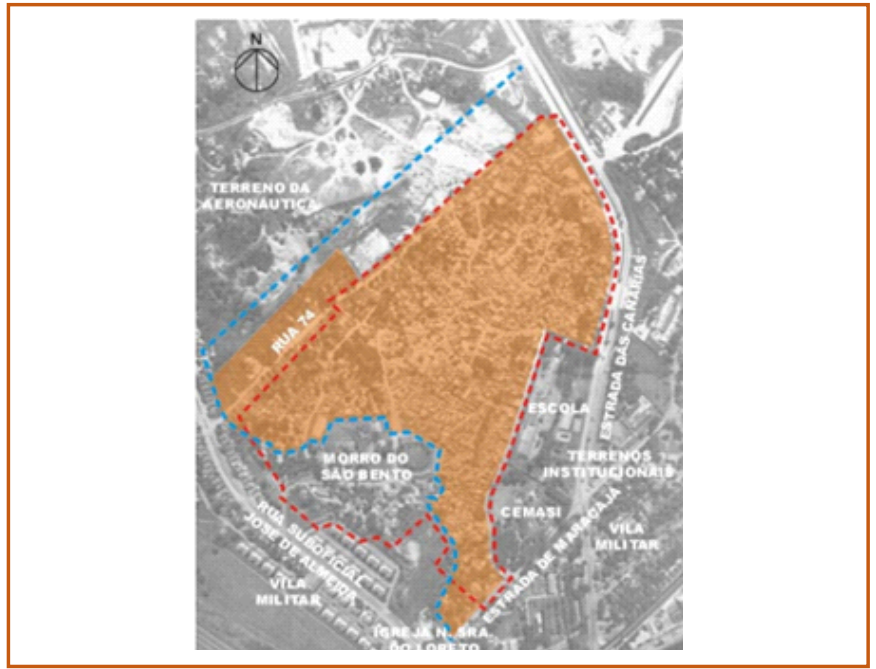

Fig. 3. Vila Joaniza oveview

A scheme of the network, containing 52 sections and 53 nodes, is shown in Fig. 4, and the respective values of length of the sections and diameter of the pipes are indicated in Table 1.

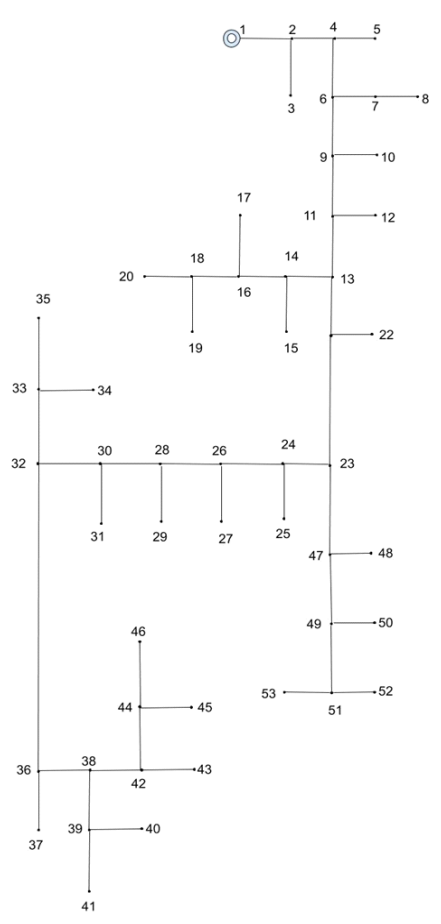

Fig. 4. Schematic drawing of the Vila Joaniza network 
TABLE I. PARAMETERS OF THE VILA JOANIZA HYDRAULIC DISTRIBUTION NETWORK

\begin{tabular}{|c|c|c|c|}
\hline Ups tream node & Downs tream node & Length (m) & Diameter (mm) \\
\hline 1 & 2 & 414,3 & 300 \\
\hline 2 & 3 & 113,6 & 50 \\
\hline 2 & 4 & 379,4 & 300 \\
\hline 4 & 5 & 285,8 & 75 \\
\hline 4 & 6 & 65,3 & 250 \\
\hline 6 & 7 & 228,3 & 100 \\
\hline 7 & 8 & 259,8 & 75 \\
\hline 6 & 9 & 7,1 & 250 \\
\hline 9 & 10 & 195,2 & 50 \\
\hline 9 & 11 & 70 & 250 \\
\hline 11 & 12 & 55,4 & 50 \\
\hline 11 & 13 & 5,5 & 250 \\
\hline 13 & 14 & 57,2 & 150 \\
\hline 14 & 15 & 56,4 & 50 \\
\hline 14 & 16 & 150,8 & 100 \\
\hline 16 & 17 & 63,4 & 50 \\
\hline 16 & 18 & 3,6 & 100 \\
\hline 18 & 19 & 49,1 & 50 \\
\hline 18 & 20 & 174,4 & 50 \\
\hline 13 & 21 & 5,9 & 250 \\
\hline 21 & 22 & 223 & 75 \\
\hline 21 & 23 & 84,8 & 250 \\
\hline 23 & 47 & 165,2 & 150 \\
\hline 47 & 48 & 69,4 & 50 \\
\hline 47 & 49 & 9,5 & 150 \\
\hline 49 & 50 & 388,9 & 75 \\
\hline 49 & 51 & 65,7 & 150 \\
\hline 51 & 52 & 227,7 & 75 \\
\hline 51 & 53 & 296,1 & 75 \\
\hline 23 & 24 & 48,2 & 200 \\
\hline 24 & 25 & 123,2 & 50 \\
\hline 24 & 26 & 140,1 & 200 \\
\hline 26 & 27 & 81,6 & 50 \\
\hline 26 & 28 & 5,3 & 200 \\
\hline 28 & 29 & 268,2 & 75 \\
\hline 28 & 30 & 151,1 & 150 \\
\hline 30 & 31 & 21,8 & 50 \\
\hline 30 & 32 & 328,4 & 150 \\
\hline 32 & 33 & 158,8 & 100 \\
\hline 33 & 34 & 35,5 & 50 \\
\hline 33 & 35 & 132,4 & 50 \\
\hline 32 & 36 & 196,2 & 150 \\
\hline 36 & 38 & 29,7 & 100 \\
\hline 38 & 39 & 36,2 & 50 \\
\hline 39 & 40 & 26,3 & 50 \\
\hline 39 & 41 & 19,6 & 50 \\
\hline 38 & 42 & 6,1 & 75 \\
\hline 42 & 43 & 43,6 & 50 \\
\hline 42 & 44 & 60 & 75 \\
\hline 44 & 45 & 21,3 & 50 \\
\hline 44 & 46 & 47,7 & 50 \\
\hline
\end{tabular}

The same values as those used in [37] were the ones entered in the SCALER. They were the total flow to be distributed over the sections, lengths of the sections, pipe diameters, formula for headloss (in this case, Hazen-Williams equation, with coefficient of roughness $C$ equal to 140), terrain elevation and pressure at the initial node of the network (node 1). The land elevation plus the pressure of the initial node (piezometric head) is interpreted by the SCALER as the water level in an upstream reservoir. It calculates the headlosses, the nodal piezometric and pressure heads, and indicates (with a red dot) the node where the pressure is the lowest of all. The initial stretch, which connects node 1 to node 2 , has no flow distribution along its length [37]. SCALER is capable of distinguishing between sections with and without distributed flow at the time of flow determination and, in this way, was able to maintain fidelity with the original system, so that comparisons could be made in a coherent way.

\section{RESUlts}

After the values described in the previous section are calculated, a SCALER screen operating the Vila Joaniza network is shown in Fig. 5. The SCALER drawing of the network of the present situation is generated by the software and shown in Fig. 6. Finally, Table 2 illustrates a comparison between the values of nodal pressures obtained by SCALER and those previously obtained by EPANET, showing absolute and relative deviations.

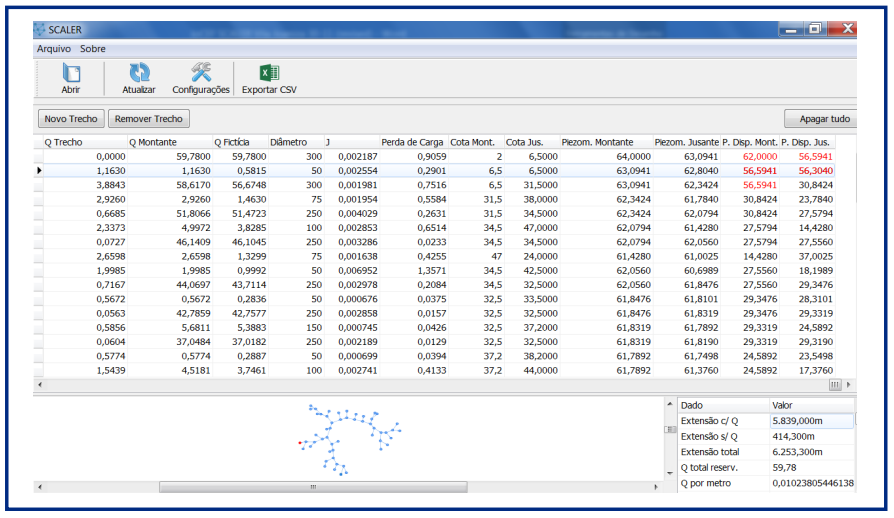

Fig. 5. SCALER interface applied to Vila Joaniza network

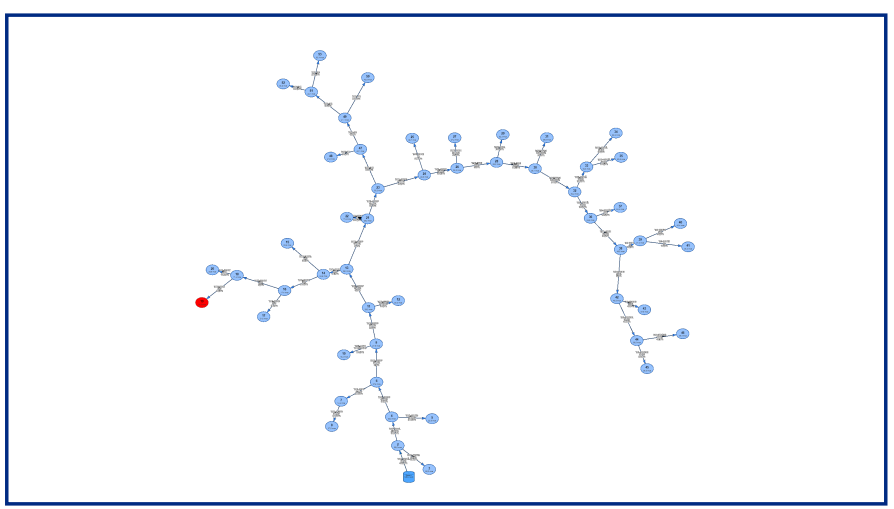

Fig. 6. SCALER drawing of the Vila Joaniza network 
TABLE II. SCALER AND EPANET PRESSURES - COMPARISON

\begin{tabular}{|c|c|c|c|c|}
\hline \multirow{2}{*}{ Node } & \multicolumn{2}{|c|}{ Nodal pressure (mH2O) } & \multirow{2}{*}{$\begin{array}{c}\text { Absolute } \\
\text { deviation } \\
\text { (mH2O) }\end{array}$} & \multirow{2}{*}{$\begin{array}{c}\text { Relative } \\
\text { deviation } \\
(\%)\end{array}$} \\
\hline & EPANET & $S C A L E R$ & & \\
\hline 1 & 62,000 & 62,000 & 0,000 & $0,000 \%$ \\
\hline 2 & 56,600 & 56,594 & 0,006 & $0,011 \%$ \\
\hline 3 & 56,320 & 56,304 & 0,016 & $0,028 \%$ \\
\hline 4 & 30,860 & 30,842 & 0,018 & $0,057 \%$ \\
\hline 5 & 23,820 & 23,784 & 0,036 & $0,151 \%$ \\
\hline 6 & 27,600 & 27,579 & 0,021 & $0,075 \%$ \\
\hline 7 & 14,460 & 14,428 & 0,032 & $0,222 \%$ \\
\hline 8 & 37,040 & 37,002 & 0,038 & $0,101 \%$ \\
\hline 9 & 27,580 & 27,556 & 0,024 & $0,087 \%$ \\
\hline 10 & 18,250 & 18,199 & 0,051 & $0,280 \%$ \\
\hline 11 & 29,370 & 29,348 & 0,022 & $0,076 \%$ \\
\hline 12 & 28,340 & 28,310 & 0,030 & $0,106 \%$ \\
\hline 13 & 29,360 & 29,332 & 0,028 & $0,096 \%$ \\
\hline 14 & 24,620 & 24,589 & 0,031 & $0,125 \%$ \\
\hline 15 & 23,580 & 23,550 & 0,030 & $0,128 \%$ \\
\hline 16 & 17,410 & 17,376 & 0,034 & $0,196 \%$ \\
\hline 17 & 21,860 & 21,821 & 0,039 & $0,179 \%$ \\
\hline 18 & 17,410 & 17,372 & 0,038 & $0,219 \%$ \\
\hline 19 & 14,380 & 14,345 & 0,035 & $0,241 \%$ \\
\hline 20 & 38,940 & 38,888 & 0,052 & $0,135 \%$ \\
\hline 21 & 29,350 & 29,319 & 0,031 & $0,106 \%$ \\
\hline 22 & 17,580 & 17,544 & 0,036 & $0,207 \%$ \\
\hline 23 & 30,190 & 30,158 & 0,032 & $0,106 \%$ \\
\hline 24 & 28,580 & 28,548 & 0,032 & $0,113 \%$ \\
\hline 25 & 36,720 & 36,682 & 0,038 & $0,103 \%$ \\
\hline 26 & 25,320 & 25,287 & 0,033 & $0,131 \%$ \\
\hline 27 & 27,210 & 27,174 & 0,036 & $0,133 \%$ \\
\hline 28 & 25,310 & 25,278 & 0,032 & $0,125 \%$ \\
\hline 29 & 52,360 & 52,312 & 0,048 & $0,091 \%$ \\
\hline 30 & 36,190 & 36,144 & 0,046 & $0,129 \%$ \\
\hline 31 & 36,680 & 36,641 & 0,039 & $0,107 \%$ \\
\hline 32 & 54,280 & 54,220 & 0,060 & $0,110 \%$ \\
\hline 33 & 54,570 & 54,509 & 0,061 & $0,111 \%$ \\
\hline 34 & 52,560 & 52,499 & 0,061 & $0,117 \%$ \\
\hline 35 & 50,630 & 50,560 & 0,070 & $0,138 \%$ \\
\hline 36 & 54,650 & 54,592 & 0,058 & $0,106 \%$ \\
\hline 37 & 54,450 & 54,383 & 0,067 & $0,122 \%$ \\
\hline 38 & 49,600 & 49,544 & 0,056 & $0,113 \%$ \\
\hline 39 & 47,490 & 47,429 & 0,061 & $0,129 \%$ \\
\hline 40 & 42,490 & 42,424 & 0,066 & $0,155 \%$ \\
\hline 41 & 45,490 & 45,427 & 0,063 & $0,139 \%$ \\
\hline 42 & 48,590 & 48,526 & 0,064 & $0,131 \%$ \\
\hline 43 & 37,570 & 37,507 & 0,063 & $0,167 \%$ \\
\hline 44 & 39,530 & 39,467 & 0,063 & $0,160 \%$ \\
\hline 45 & 36,530 & 36,464 & 0,066 & $0,180 \%$ \\
\hline 46 & 39,510 & 39,442 & 0,068 & $0,171 \%$ \\
\hline 47 & 39,740 & 40,144 & $-0,404$ & $-1,010 \%$ \\
\hline 48 & 41,170 & 41,572 & $-0,402$ & $-0,973 \%$ \\
\hline 49 & 40,720 & 41,121 & $-0,401$ & $-0,980 \%$ \\
\hline 50 & 43,400 & 43,778 & $-0,378$ & $-0,866 \%$ \\
\hline 51 & 47,670 & 48,067 & $-0,397$ & $-0,829 \%$ \\
\hline 52 & 38,380 & 38,775 & $-0,395$ & $-1,023 \%$ \\
\hline 53 & 52,060 & 52,449 & $-0,389$ & $-0,745 \%$ \\
\hline
\end{tabular}

\section{DISCUSSION}

It was shown that the modular deviations between the nodal pressures calculated by EPANET and those by SCALER were quite small. These were, in absolute and relative terms, respectively, $0.404 \mathrm{mH} 2 \mathrm{O}$ (node 47 ) and $1.023 \%$ (node 52 ) as a maximum value, and $0.089 \mathrm{mH} 2 \mathrm{O}$ and $0.233 \%$ as an average value. Therefore, the results corroborate the good functioning of the SCALER software also for networks with a large number of branches.

\section{REFERENCES}

[1] A. L. Amorim, Conflict resolution mechanism in shared river basins, Ph.D. Thesis. Federal University of Campina Grande, Brazil, 2016. http://dspace.sti.ufcg.edu.br:8080/jspui/handle/riufcg/16863.

[2] Strategic Studies Center of Fundação Oswaldo Cruz, "About 2.2 billion people do not have drinking water in the world, according to UN report," CeeFiocruz Report. Access on: May 12, 2021 [Cerca de 2,2 bilhões de pessoas não têm água potável no mundo, aponta relatório da $\mathrm{ONU}]$. https://cee.fiocruz.br/?q=agua-potavel-no-mundo.

[3] J. M. Azevedo Netto, M. F. Fernandez, R. Araujo, and A. E. Ito, Hydraulics Manual, 8th ed. São Paulo: Blucher, 2013, pp. 465-476 [Manual de Hidráulica].

[4] R. A. Wurbs, Computer Models for Water Resources Planning and Management, IWR Report 94-NDS-7. Texas A\&M University, Texas, USA, 1994

[5] T. Wagener, D. Savic, D. Butler, R. Ahmadian, Tom Arnot, et al., "Hydroinformatics education - the water informatics in science and engineering (WISE) centre for doctoral training," Hydrol. Earth Syst. Sci., vol. 25, pp. 2721-2738, 2021. doi: https://doi.org/10.5194/hess-25-27212021.

[6] M. T. Tsutiya, Water Supply, 3rd ed. São Paulo: Poli/USP, 2006, pp. 1-8 [Abastecimento de Água].

[7] A. Muhammetoglu, H. Muhammetoglu, A. Adigüzel, Ö. İritaş, and Y. Karaaslan, "Management of water losses in water supply and distribution networks in Turkey," Turkish J. Water Sci. Manag., vol. 2, no. 1, pp. 5875, 2018. doi: https://doi.org/10.31807/tjwsm.354298.

[8] T. M. Walski, D. V. Chase, D. A. Savic, W. Grayman, S. Beckwith, et al., Advanced Water Distribution Modeling and Management: Operations. Haestad Press, 2004, pp. 297-303; 417-497.

[9] T. M. Walski, "Optimization and pipe sizing decisions," J. Water Resour. Plan. Manag., vol. 121, no. 4, pp. 340-343, 1995. doi: https://doi.org/10.1061/(ASCE)0733-9496(1995)121:4(340).

[10] S. D. C. Jericó; R. O. Fernandes; and J. F. da Silva, "Hydraulic evaluation of the water supply network in the city of Várzea Alegre - CE," XX Brazilian symposium on water resources, Bento Gonçalves, Brazil, pp. 18,2013 [Avaliação hidráulica da rede de abastecimento de água da cidade de Várzea Alegre - CE]. https://abrh.s3.sa-east1.amazonaws.com/Sumarios/155/52104f79908ab9e6732fb26e260b28c8 _c8b1a59eb6cce8966f8549ceb2cdd971.pdf

[11] S. H. A. Razaq Zyoud, Hydraulic performance of Palestinian water distribution systems: Jenin water supply network as a case study, M.Sc. Thesis. An-Najah National University, Nablus, Palestine, 2003. http://www.secheresse.info/spip.php?article69442.

[12] A. M. A. Sattar, Ö. F. Ertuğrul, B. Gharabaghi, E. A. McBean, and J. Cao, "Extreme learning machine model for water network management," Neural. Comput. Appl., 2019 [Nat Comput Applications Forum, 2017]. doi: https://doi.org/10.1007/s00521-017-2987-7.

[13] R. Dziedzic and B. W. Karney, "Performance index for water distribution networks under multiple loading conditions," J. Water Resour. Plann. Manage., vol. 142, no. 1, pp. 04015040-1-04015040-11, 2016. doi: https://doi.org/10.1061/(ASCE)WR.1943-5452.0000564.

[14] P. A. Holanda, J. P. L. Félix, F. C. G. Silva Jr., J. A. Fernandes, and F. A. M. Ponce, "Hydraulic modeling of the water distribution network in the district of Vazantes / CE using EPANET software," 49th ASSEMAE national sanitation congress, Cuiabá, Brazil, pp. 97-110, 2019 [Modelagem hidráulica da rede de distribuição de água do distrito de 
Vazantes / CE utilizando o software EPANET]. https://tratamentodeagua.com.br/artigo/modelagem-hidraulica-rededistribuicao-agua-ce/.

[15] M. Tabesh and A. Dolatkhahi, "Effects of pressure dependent analysis on quality performance assessment of water distribution netwoks," Iran J Sci Technol Trans B Eng, vol. 30, no. B1, pp. 119-128, 2006. https://ijstc.shirazu.ac.ir/article 768.html.

[16] N. J. H. Al-Mansori, T. J. M. Al-Fatlawi, and L. S. A. Al-Zubaidi, "Equilibrium of Babylon water supply network using EPANET program," Plant Arch., vol. 20, no. 2, 2020 pp. 693-700, 2020. http://www.plantarchives.org/SPL\%20ISSUE\%2020-2/101_693700_.pdf.

[17] A. S. H. Al-Mamori and N. Al-Musawi, "Simulation of chlorine decay in Al-Gukook water distribution networks using EPANET," IJSR, vol. 6, no. 10, pp. 949-955, 2017. https://www.ijsr.net/archive/v6i10/ART20177333.pdf.

[18] M. E. Aydin, S. Aydin, and F. Beduk, "Water loss and control in drinking water networks in Turkey," Regional workshop on solutions to water challenges in MENA-Region, Cairo, Egypt, 2017. https://www.researchgate.net/publication/343916485.

[19] A. Mamade, D. Loureiro, H. Alegre, and D. Covas, "Top-down and bottom-up approaches for water-energy balance in portuguese supply systems," Water, vol. 10, no. 5, pp. 1-14, 2018. doi: https://doi.org/10.3390/w10050577.

[20] S. Heydari, J. Mamizadeh, J. Sarvarian, and G. Ahmadi, “Optimization of water distribution networks using developed binary genetic algorithm and hydraulic model software," J. appl. res. water wastewater, vol. 7, no. 1, pp. 30-35, 2020. doi: https://dx.doi.org/10.22126/arww.2020.5061.1159.

[21] I. Eker, M. J. Grimble, and T. Kara, "Operation and simulation of city of Gaziantep water supply system in Turkey," Renew. Energy, vol. 28, no. 6, pp. 901-916, 2003. doi: https://doi.org/10.1016/S09601481(02)00095-2.

[22] R. Sitzenfrei, Q. Wang, Z. Kapelan, and Dragan Savić, "Using complex network analysis for optimization of water distribution networks," Water Resour. Res., vol. 56, no. 8, pp. 1-17, 2020. doi: https://doi.org/10.1029/2020WR027929.

[23] M. Tabesh, M. R. Delavar; and A. Delkhah, "Use of geospatial information system based tool for renovation and rehabilitation of water distribution systems," Int. J. Environ. Sci. Tech., vol. 7, no. 1, pp. 47-58, 2010. doi: https://doi.org/10.1007/BF03326116.

[24] N. R. Kadhim, K. A. Abdulrazzaq, and A. H. Mohammed, "The management of water distribution network using GIS application case study: AL-Karada area," J. Phys.: Conf. Ser. 1895 012038, 2021. doi:10.1088/1742-6596/1895/1/012038.

[25] S. Aburawe and A. R. Mahmud, "Water loss control and real-time leakage detection using GIS technology," Geomatics Technologies in the City Symposium, Jeddah, Saudi Arabia, 2011. https://www.researchgate.net/publication/330038831.

[26] A. F. Morosini, F. Costanzo, P. Veltri, and D. Savić, "Identification of measurement points for calibration of water distribution network models," Procedia Engineering, vol. 89, no. 2014, pp. 693-701, 2014. doi: https://doi.org/10.1016/j.proeng.2014.11.496.

[27] A. H. Al Aboodi, S. A. Abbas, and A. S. Dawood, "Hydraulic network model of water distribution system in Al Hakeem Quarter, Maqil District, Basrah, South of Iraq," Int. j. sci. eng. res., vol. 5, no. 10, pp. 570-574, 2014. https://www.researchgate.net/publication/283583180.

[28] S. Rathi, "S-PLACE GA for optimal water quality sensor locations in water distribution network for dual purpose: regular monitoring and early contamination detection - a software tool for academia and practitioner," Water Supply, vol. 21, no. 2, pp. 615-634, 2021. doi: https://doi.org/10.2166/ws.2020.333.

[29] E. Luvizotto Jr. and H. S. Pizzo, "Properties and analysis of searching techniques for calibrating a water distribution network with a model," Acta Univ Carol, Geol, vol. 46, no. 2/3, pp. 282-285, 2002 [Proceedings 4th International Conf. Calibration and Reliability in Groundwater Modelling, Czech Republic, 2002].

[30] S. Liu, W. Liu, J. Chen, and Q. Wang., "Optimal locations of monitoring stations in water distribution systems under multiple demand patterns: a flaw of demand coverage method and modification," Front Environ Sci
Eng, vol. 6, pp. 204-212, 2012. doi: https://doi.org/10.1007/s11783-0110364-9.

[31] A. K. Soares, L. F. R. Reis, "Water distribution models calibration using pressure-directed hydraulic simulation model (MSHDP) and hibrid method GA-Simplex," Rev. Bras. de Recur. Hidr., vol. 9, no.2, pp. 8596, 2004. doi: http://dx.doi.org/10.21168/rbrh.v9n2.p85-96.

[32] H. S. Pizzo, E. Luvizotto Jr., and R. M. R. da Silva, "Water distribution network models calibration: alternative method (CNM) for identifying monitoring stations," Int. j. sci. eng. investig., vol. 10, no 111., pp 49-57, 2021. http://www.ijsei.com/papers/ijsei-1011121-07.pdf.

[33] S. Q. Aziz, M. Yassen, M. Qader, and R. Pishtiwan, Water supply system design for Aram Village, Erbil-Iraq, Poster Report. Salahaddin University, Erbil, Iraq, 2018. https://www.researchgate.net/publication/329000190_Water_Supply_Sy stem_Design_for_Aram_Village_Erbil-Iraq.

[34] S. Q. Aziz, B. Kareem, D. Fakher, and Z. Kareem, Design of Water Distribution System for Zin City, Erbil-Iraq, Poster Report. Salahaddin University, Erbil, Iraq, 2019. https://www.researchgate.net/publication/332411129_Design_of_Water _Distribution_System_for_Zin_City_Erbil-Iraq.

[35] S. Q. Aziz, B. A. Salih, H. M. Badir, and M. I. Tawfiq, Water distribution system design for New Zanco Village, Erbil-Iraq, Poster Report. Salahaddin University, Erbil, Iraq, 2017. doi: http://dx.doi.org/10.13140/RG.2.2.20803.40487.

[36] J. Lemgruber, L. Musumeci, P. V. L. Lopes, B. M. Mourão, and L. L. Paris, Diagnosis of violence and coexistence in Vila Joaniza, Rio de Janeiro, Center for Safety and Citizenship Studies Report. Rio de Janeiro, Brazil, 2012 [Diagnóstico da violência e da convivência em Vila Joaniza, Rio de Janeiro]. https://cesecseguranca.com.br/textodownload/diagnostico-da-violenciae-da-convivencia-em-vila-joaniza-rio-de-janeiro/.

[37] D. B. Okumura and L. R. L. Ramírez, Design study of the water supply network for Vila Joaniza / Ilha do Governador, B.Sc. Report. Federal University of Rio de Janeiro, Brazil, 2012 [Estudo de concepção da rede de abastecimento de água para a Vila Joaniza / Ilha do Governador]. http://drhima.poli.ufrj.br/images/documentos/tcc/2012/daniel-barbosa2012.pdf.

[38] Associação Brasileira de Normas Técnicas, NBR 12218: Water distribution network project for public supply - Procedure, 2 nd ed. Rio de Janeiro: ABNT, 2017, pp. 1-29 [Projeto de rede de distribuição de água para abastecimento público - Procedimento].

[39] Q. Wang, D. A. Savić, and Z. Kapelan, "GALAXY: a new hybrid MOEA for the optimal design of water distribution systems," Water Resour. Res., vol. 53, no. 3, pp. 1997-2015, 2017. doi: https://doi.org/10.1002/2016WR019854.

[40] M. Shimada, "Time-marching approach for pipe steady flows," J Hydraul Eng, vol. 114, no. 11, pp. 1301-1320, 1988 . doi: https://doi.org/10.1061/(ASCE)0733-9429(1988)114:11(1301).

[41] Luvizotto Jr., E., Computer-aid operational control of water supply systems, Ph.D. Thesis. University of São Paulo, Brazil, 1995 [Controle operacional de redes de abastecimento de água auxiliado por computador]. https://repositorio.usp.br/item/000742270.

[42] R. M. R. Silva, C. B. M. Ribeiro, and H. S. Pizzo, "Flow - integrated hydraulic calculation software for water supply systems," J. multidiscip. eng. sci. technol., vol. 8, no. 1, pp. 13386-13399, 2021. https://www.jmest.org/wp-content/uploads/JMESTN42353658.pdf.

[43] F. A. Diuana and S. C. C. P. Ogawa, Comparative analysis of hydraulic models EPANET, WaterCAD and UFC system for water supply systems - distribution network, B.Sc. Report. Federal University of Rio de Janeiro, Brazil, 2015 [Análise comparativa dos modelos hidráulicos EPANET, WaterCAD e sistema UFC para sistemas de abastecimento de água - rede de distribuição]. https://monografias.poli.ufrj.br/repdownload.php? farquivo $=$ monopoli10013745.pdf\& $f$ codigo $=1951$.

[44] D. Riccaldone, Comparison of sizing of water distribution networks by computational models, B.Sc. Report. Federal University of Ouro Preto, Brazil, 2016 [Comparação de dimensionamento de redes de distribuição de água por modelos computacionais]. https://www.monografias.ufop.br/handle/35400000/396. 
[45] J. P. C. Ignácio, M. V. Nascimento, P. H. G. Oliveira, R. Platz, and H. S. Pizzo, "SCALER - software for sizing water distribution networks," Brazilian Journal of Development, vol.7, no.7, pp. 71854-71877, 2021 [SCALER - software para dimensionamento de redes de distribuição de água]. doi: https://doi.org/10.34117/bjdv7n7-387.
[46] E. Tourasse, "Explicit equation for coefficient of friction and duct calculation," Eng. Sanit., vol. 25, no. 2, pp. 177-178, 1986 [Equação explícita para o coeficiente de atrito e cálculo de condutos]. 